\title{
The HTA Core Model: A novel method for producing and reporting health technology assessments
}

\section{Kristian Lampe}

Finnish Office for Health Technology Assessment

\section{Marjukka Mäkelä}

Finnish Office for Health Technology Assessment and University of Copenhagen

\section{Marcial Velasco Garrido}

Technische Universität Berlin

\section{Heidi Anttila}

Finnish Office for Health Technology Assessment

\section{Ilona Autti-Rämö}

Finnish Office for Health Technology Assessment and The Social Insurance Institution and Hospital for Children and Adolescents, University of Helsinki

\author{
Nicholas J. Hicks \\ University of Southampton
}

\section{Björn Hofmann}

Norwegian Knowledge Centre for the Health Services and University College of Gjøvik

\section{Juha Koivisto}

National Institute for Health and Welfare, Finland

\section{Regina Kunz}

University Hospital Basel

\section{Pia Kärki}

Finnish Office for Health Technology Assessment

\section{Antti Malmivaara}

Finnish Office for Health Technology Assessment

\section{Kersti Meiesaar \\ University of Tartu}

\footnotetext{
The authors thank the Partners in the EUnetHTA Work Package 4 and colleagues of partner institutions that contributed to the work. The list of individuals and partner institutions and other colleagues who have contributed to the work can be found in Reference 17. This study was undertaken within the framework of the European network for Health Technology Assessment (EUnetHTA) project, which was supported by a grant from the European Commission (Grant agreement 2005110 project 790621). The study was also funded by the Finnish Office for Health Technology Assessment (FINOHTA) of the National Research and Development Centre for Welfare and Health (STAKES). The sole responsibility for the content of this publication lies with the authors and the European Commission is not responsible for any use that may be made of the information contained therein.
} 
Lampe et al.

Päivi Reiman-Möttönen

Finnish Office for Health Technology Assessment

Inger Norderhaug

Norwegian Knowledge Centre for the Health Services and University of Trømso

Iris Pasternack

Finnish Office for Health Technology Assessment

Alberto Ruano-Ravina

Galician Department of Health and University of Santiago de Compostela

Pirjo Räsänen

Finnish Office for Health Technology Assessment

Ulla Saalasti-Koskinen

Finnish Office for Health Technology Assessment

Samuli I. Saarni

Finnish Office for Health Technology Assessment and Helsinki University and Helsinki

University Hospital

Laura Walin

University of Helsinki

Finn Børlum Kristensen

National Board of Health, Copenhagen, Denmark and University of Southern Denmark

\section{for the European network for Health Technology Assessment (EUnetHTA)}

Objectives: The aim of this study was to develop and test a generic framework to enable international collaboration for producing and sharing results of health technology assessments (HTAs).

Methods: Ten international teams constructed the HTA Core Model, dividing information contained in a comprehensive HTA into standardized pieces, the assessment elements. Each element contains a generic issue that is translated into practical research questions while performing an assessment. Elements were described in detail in element cards. Two pilot assessments, designated as Core HTAs were also produced. The Model and Core HTAs were both validated. Guidance on the use of the HTA Core Model was compiled into a Handbook.

Results: The HTA Core Model considers health technologies through nine domains. Two applications of the Model were developed, one for medical and surgical interventions and another for diagnostic technologies. Two Core HTAs were produced in parallel with developing the model, providing the first real-life testing of the Model and input for further development. The results of formal validation and public feedback were primarily positive. Development needs were also identified and considered. An online Handbook is available. Conclusions: The HTA Core Model is a novel approach to HTA. It enables effective international production and sharing of HTA results in a structured format. The face validity of the Model was confirmed during the project, but further testing and refining are needed to ensure optimal usefulness and user-friendliness. Core HTAs are intended to serve as a basis for local HTA reports. Core HTAs do not contain recommendations on technology use.

Keywords: Technology assessment, Biomedical, Research design, Classification, Internet, Medical Informatics applications 
The task of Work Package 4 (WP4) of the European network for Health Technology Assessment (EUnetHTA) Project was to develop a multidisciplinary common core of health technology assessment (HTA) evidence $(15 ; 17)$. This article provides an overview of WP4, with particular focus on the HTA Core Model, a framework to guide the production and reporting of HTAs. Another article discusses piloting the model and its applications in greater detail (23).

Health technologies vary in their type or material nature (i.e., what they are) and application area or purpose (i.e., what they are used for) (22). It is likely that different combinations of the type and application area require different things to be considered in an assessment. An assessment of a drug used for treating a disease most likely warrants different research questions compared with an assessment of a personal rehabilitation program. We built a model applicable in two situations: assessment of medical and surgical interventions and assessment of diagnostic technologies.

\section{AIMS AND OBJECTIVES}

We aimed at developing a framework that enables effective collaboration and sharing of information to overcome two main challenges of contemporary HTA: variance in the extent and scope of analysis, and differences in reporting the results. This could enhance the international applicability of national or regional HTA reports $(1 ; 5 ; 10 ; 11)$.

We built on earlier work of the EUR-ASSESS and ECHTA/ECAHI projects and relevant textbooks $(2 ; 5$; $12 ; 13 ; 16 ; 18 ; 21)$. Instead of repeating methodological guidance already available, we aimed at the following: operationalizing the questions that should be asked and answered within HTA, providing an overview of state-of-the-art methodologies, and defining and standardizing the structure of the final product - the HTA report.

\section{STRUCTURE AND METHODS}

\section{Structure}

WP4 included twenty-four organizations from seventeen countries, led by the Finnish Office for Health Technology Assessment (17). Multinational participation in teams and meetings ensured variability of views.

Results of our work can be found in the two models that were developed during the project, collectively referred to as the HTA Core Model. A model to assess medical and surgical interventions was first compiled, and subsequently a model to assess diagnostic technologies. Both applications were tested by producing and validating two actual assessments, the Core HTAs. Key instructions were compiled into a handbook (19).

\section{Working Method}

Basic principles and working methods were discussed and agreed on in the Lead Partner's coordinating team and in the general design team. More detailed work was performed in several domain teams, each of which focused on one domain of HTA. Sixty investigators (three to ten per domain team) from twelve countries participated and thirty-four reviewers commented on the work. A coordinator and a primary investigator were appointed for each domain team. Experts within teams are listed elsewhere $(10 ; 11)$.

Much of the work was accomplished through discussing and circulating draft documents over e-mail. Four general face-to-face meetings and some smaller meetings constituted an integral part of the work. Patient perspectives were discussed in two further meetings. Details of meeting topics and participants are available in WP4 Technical Report (7).

\section{Designing the HTA Core Model}

The Core. Before developing any practical tools, we agreed on what the core of HTA would mean. It should include that which is most useful or significant to share between countries, regions, or other settings. We acknowledged that HTA could be perceived in two, mutually exclusive, ways that have a fundamental impact on how one perceives the core. First, one might perceive certain aspects of HTA, for example, those studying effectiveness or health economics, as being more significant than other aspects and consequently being closer to the core. On the other hand, one might argue that any aspect of technology might be crucially relevant when deciding on technologies. Hence, being in the core would not be a directly result from belonging to a specific domain (e.g., effectiveness or ethics); rather there would be a priority order within domains. These were illustrated by two alternative ways of splitting an onion (Supplementary Figure 1, which is available at www.journals.cambridge.org/thc2009001).

We chose to split the onion horizontally into rings, and regard each domain as equally valuable. Hence, we subscribed to the multidisciplinary nature of HTA, which with its wide scope provides decision makers with relevant information. We aimed to accomplish this by defining a collection of standardized issues that are considered in an HTA. Each issue can be either closer to the core (i.e., more significant) or further away from it.

Domains, Topics, and Issues. We worked on the following nine domains originally defined in the EURASSESS project (21): Health problem and current use of the technology (implementation level); Description and technical characteristics of technology; Safety; Clinical effectiveness; Costs, economic evaluation; Ethical analysis; Organizational aspects; Social aspects; and Legal aspects.

A tenth domain was added for Accuracy of diagnostic technologies. Its somewhat controversial role is discussed below.

A domain is a wide framework, representing an angle from which to view the use, consequences, and implications of any technology. The domain teams were first asked to agree on a definition of the domain they were working 
on. The definition focused teams' efforts and provided indications of possible overlap with other domains. Next, the teams identified topics (more specific areas of consideration) within their domain and even more specific issues within the topics. One domain was divided into several topics. Issues within the topics were defined as even more specific areas of consideration in any of the topics. An issue was to be expressed as a question that would be used in defining the assessment protocol (Supplementary Table 1, which is available at www.journals.cambridge.org/thc2009001).

The domain teams then formulated their work into assessment elements and element cards.

Assessment Elements. The combination of a domain, topic, and issue was viewed as the basic unit of the model and labeled as an assessment element. It defines a piece of information that describes the technology, or the consequences or implications of its use, or the patients and the disease for which it is applied. In the context of clinical research, an element may describe a clinical outcome (e.g., reduction of symptoms), whereas in social science an element may describe the impact of technology on patient's life (e.g., ability to work). The nature of elements may vary across domains since the consequences and implications are understood and studied differently. Each element outlines a set of information that may be useful when deciding on the use or nonuse of technology.

As the number of possible elements of HTA is very large, we focused on elements that deal with context-independent (i.e., easily transferable) information, and elements that are particularly significant from the viewpoint of HTA (even if these would not be easily transferable). Hence, transferability and importance became key characteristics of the elements.

Element Cards. We gave the conceptual assessment elements a more tangible format in the form of cards. Each element card describes one assessment element in more detail by indicating, for example, suggested research methodologies. The descriptions are generic in nature, that is, they are not specific to any technology. The cards can be used in relevant tools, for example, in information technology applications. Supplementary Table 2, which is available at www.journals.cambridge.org/thc2009001, presents the content of the cards.

Teams defined and structured their domains, suggested suitable assessment methodologies, and developed assessment elements. They also considered the importance and transferability of each issue to define whether it belonged to the Core.

\section{Piloting the HTA Core Model}

Core HTAs. Each model was tested through conducting a pilot assessment. Technologies used for piloting were selected through a voting process that is explained in further detail elsewhere $(7 ; 23)$. We selected technologies that have
Table 1. Examples of Suggestions, Recommendations, and Standards in Element Cards

\begin{tabular}{|c|c|}
\hline $\begin{array}{l}\text { Content of field "Information } \\
\text { sources" }\end{array}$ & Nature of recommendation \\
\hline Database X can be used & Suggestion \\
\hline $\begin{array}{l}\text { Use of Database } X \text { is } \\
\text { recommended }\end{array}$ & Recommendation \\
\hline $\begin{array}{l}\text { Database X shall be used to } \\
\text { check Y }\end{array}$ & Standard \\
\hline $\begin{array}{l}\text { A systematic literature review } \\
\text { may be useful }\end{array}$ & Suggestion \\
\hline $\begin{array}{l}\text { A systematic literature review is } \\
\text { recommended }\end{array}$ & Recommendation \\
\hline $\begin{array}{l}\text { A systematic literature review } \\
\text { shall be conducted }\end{array}$ & Standard \\
\hline $\begin{array}{l}\text { A systematic literature review } \\
\text { shall be conducted using the } \\
\text { methodology described in the } \\
\text { Cochrane Handbook for } \\
\text { Systematic Reviews of } \\
\text { Interventions }\end{array}$ & $\begin{array}{l}\text { Standard with detailed } \\
\text { requirements regarding } \\
\text { methodology }\end{array}$ \\
\hline
\end{tabular}

broad relevance in the European context and that would allow an extensive testing of the models.

When conducting the Core HTAs, teams first looked through the list of the assessment elements, considering whether each element is relevant for the technology to be assessed. If relevant, an answer to the issue question should be found within the Core HTA. If the model suggested an irrelevant issue, finding an answer could be omitted.

Next, the researchers converted relevant issues into actual research questions. (See Supplementary Table 3, which is available at www.journals.cambridge.org/thc2009001, for examples.) The issues within the model present problems on a general level only; each research group needs to translate them into research questions. The Core HTA should provide answers to these questions.

The model guides researchers in selecting which aspect of technology, or its use, they should study. Research tradition and guidelines within each scientific domain steer the process.

The element cards provide guidance on how to answer the actual research questions. Particularly, the information sources field in the cards may contain useful suggestions, recommended research methodologies, or even common research standards if so desired (Table 1).

The Core HTAs were produced in parallel with developing and refining the respective models. The aim was an iterative process where the experience gained by answering the questions feeds back to the model. Details of the work are available elsewhere $(10 ; 11 ; 23)$.

\section{Validation}

A triangulation process was used to ensure the validity of the HTA Core Model and the two pilot Core HTAs. 
Producing Core HTAs provided first-hand experience of using the model. Each domain team thus could make necessary changes to the model.

Both models and core HTAs were formally validated through an online questionnaire. Members of EUnetHTA and INAHTA (International Network of Agencies for Health Technology Assessment) were invited to participate. While validating the HTA Core Model, respondents were asked to compare the model with one of their own ongoing projects or with a completed full HTA. Due to the large number of elements, respondents were asked to comment on three domains they had not worked on during the model development. Overall percentages from validation questionnaires were counted and themes from free comments were collected.

Feedback from a third angle was sought through a public consultation process using a standard feedback form. Some key validation results are available in this article and elsewhere $(7 ; 23)$. To discuss the challenges, primary investigators were asked to consider what were the most difficult aspects and greatest steps forward in developing the HTA Core Model.

\section{RESULTS OF THE PROJECT}

\section{The HTA Core Model}

The HTA Core Model contains an ontology defining the information content in a comprehensive HTA and a new way to structure HTA information, and methodological guidance.

General structure. Assessment elements used in applying the Model are all drawn from the same pool of elements. Not all elements, however, belong to all applications. On the other hand, the element cards are applicationspecific. Hence, an element that provides information on the formal approval of technology may contain distinct definitions within different applications of the model.

Currently the domains contain three to eight topics divided into six to thirty-one issues. The intervention model contains 133 assessment elements while the diagnostic model contains 153 .

\section{Characteristics and Relationships of Domains.}

A natural way of starting an HTA is to describe the technology that is under assessment, relevant health problems and alternative technologies. This lays the foundation for further domains that are commonly considered in HTAs: evaluation of the effectiveness, safety, and economic aspects. These three domains often use the PICO structure, defining in detail the population (P), intervention (I), comparators $(\mathrm{C})$, and outcomes $(\mathrm{O})$. Only outcomes are domainspecific.

The remaining four domains-ethical, organizational, social, and legal aspects-also often focus on defined patients and interventions but differ in the way they frame their elements. Organizational and social aspects map the challenges, resources, possible actions, and consequences of using the technology. The legal domain relies on legislative documents in each context. In ethical analysis, all relevant stakeholders must be defined to consider their viewpoints on using the technology. Ethical thinking also should be integrated into the entire HTA process, to ensure that key ethical principles are considered and respected (24).

Overlapping Issues. We discovered that the issues discussed within various domains occasionally sound very similar. The same may apply to issues that belong to the same domain, but under different topics. We allowed similar issues across the domains in the Model under the following condition: If two issues that look similar at first glance are genuinely different, that is, they would be analyzed differently within two different domains/topics, they constitute two separate assessment elements. However, issues largely perceived and analyzed similarly within both domains/topics would constitute a single assessment element common to both domains/topics.

Inclusion in the Core. Not all elements defined in the ontology belong to the core. We decided to include an element in the core based on two basic characteristics-its transferability and importance.

Transferability was an obvious factor to consider: any information specific to a particular context (e.g., region, country, healthcare system) would seldom be useful in other settings. Fully or partly transferable information might instead provide valuable input beyond its original production location.

Importance was considered to ensure that the core is sufficiently robust, containing significant information from the viewpoint of HTA. Issues perceived important from the viewpoint of HTA are often useful also in making policy decisions, but importance considered here is not equal to relevance for a particular policy question.

Importance and transferability are independent of each other. Issues that are very important to consider may contain data that are only partly transferable to other settings. Likewise, easily transferable issues are not always significant from the viewpoint of HTA.

Inclusion in the core is defined according a Core Matrix (Table 2) that divides assessment elements into core elements and noncore elements. A third, borderline category was used

Table 2. The Core Matrix

\begin{tabular}{|c|c|c|c|c|}
\hline \multicolumn{2}{|c|}{ Core matrix } & \multicolumn{3}{|c|}{ Importance } \\
\hline & & Optional & Important & Critical \\
\hline \multirow[t]{3}{*}{ Transferability } & Complete & Not core & Core & Core \\
\hline & Partially & Not core & Core & Core \\
\hline & Not & Not core & Not core & Core \\
\hline
\end{tabular}

Note. Gray fields indicate combinations originally defined as borderline. 
during the development process. Between 44 percent and 88 percent of the assessment elements in the domains were regarded as Core Elements in the early drafts of the Model, while the majority of the rest were of borderline category, and only a few of the noncore category. In the final Core Matrix, most elements in the borderline category were suggested to be included in the core.

Domain Methodologies. Domain teams refrained from specifying HTA methods further than recommending state-of-the-art methods. The ethical domain describes several alternative methods, to be selected and tailored by topic and organization. Domain teams working on organizational and social aspects preferred the translational model over diffusion model for understanding development and diffusion of technologies (20). The translational model presumes technologies undergo changes when applied in specific environments. Hence, it is essential to consider which resources a new technology utilizes and how these are affected by the technology.

Systematic reviews are not necessary for all domains; for example, reviewing all current indications of a technology such as MRI scanning would be a vast and useless effort. Instead, information could be gathered from available secondary studies (HTAs, guidelines) until no new indications appear.

\section{Principles for the Use of the HTA Core Model}

We considered various uses of the HTA Core Model and agreed that the primary use should be the production of Core HTAs. This comprehensive and multidisciplinary assessment is conducted using the HTA Core Model and has considered all core elements. It contains a summary of findings in each domain, but refrains from giving recommendations on using the technology. Through its wide scope, focus on core elements, and summary chapter, a Core HTA offers an overview of a technology that is likely to be useful in the European context. A Core HTA can be used as a basis for producing local HTA reports that take into account local circumstances, for example, epidemiology, organization, resources, and values.

An alternative, secondary, use would involve a more liberal selection and use of various assessment elements, perhaps from only one or a few of the domains. The needs and interests of the user define the extent of analysis.

Both the Core HTAs and more liberal use of the HTA Core Model result in a pool of Structured HTA Information that can be used for local HTAs. The HTA Core Model and the resulting Core HTAs and local HTAs were collectively designated as the Core HTA Structure (Figure 1).

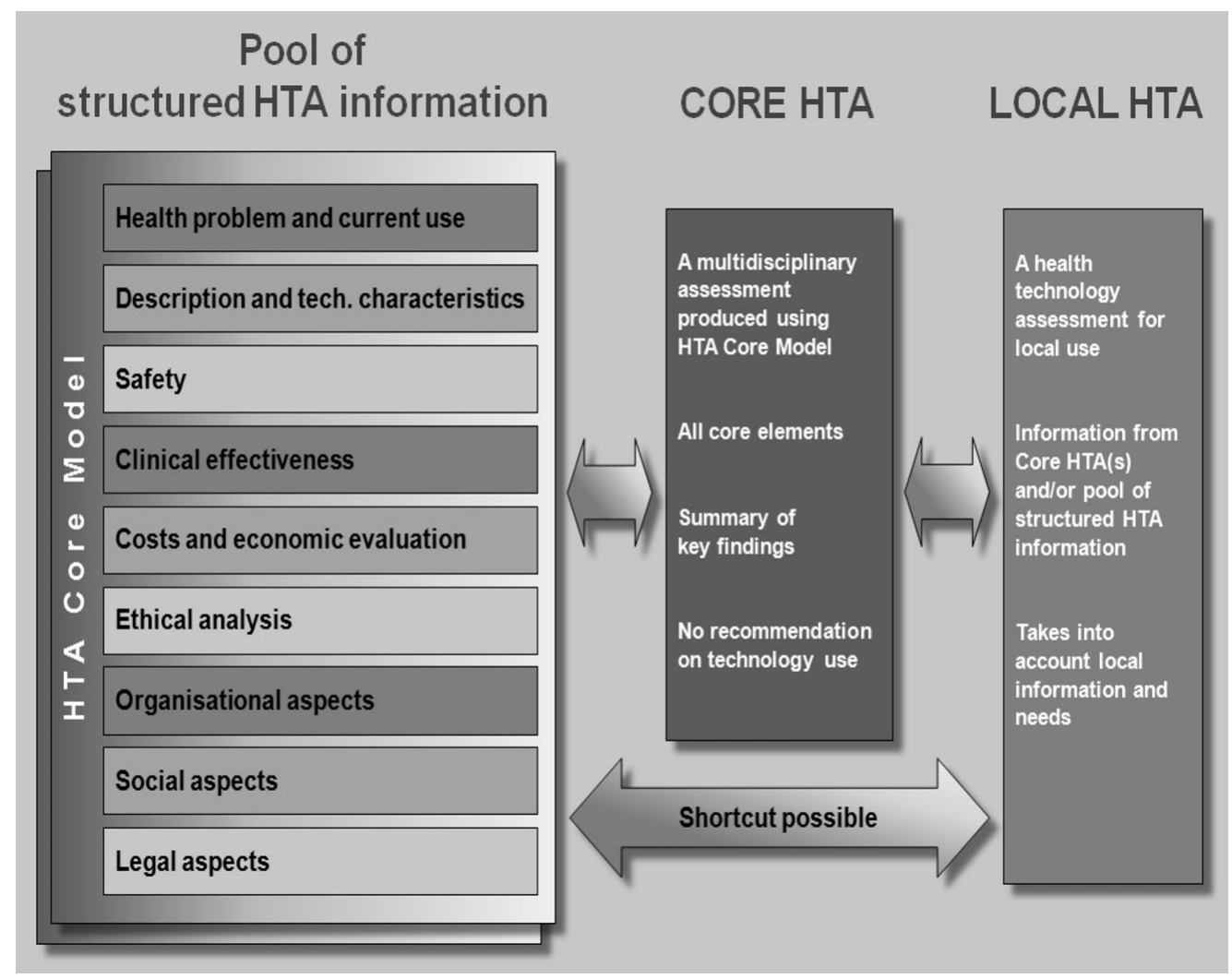

Figure 1. The core health technology assessment structure. 
Table 3. Results of the General Questions of the HTA Core Model Validation

\begin{tabular}{|c|c|c|c|c|c|c|}
\hline \multirow[b]{2}{*}{$\begin{array}{l}\text { Evaluation topic (Exact statements } \\
\text { available in Technical Report) }\end{array}$} & \multicolumn{2}{|c|}{$\begin{array}{c}\text { Share of respondents that } \\
\text { agreed or strongly agreed with } \\
\text { the statement }(\%)\end{array}$} & \multicolumn{2}{|c|}{$\begin{array}{c}\text { Share of respondents that } \\
\text { disagreed or strongly } \\
\text { disagreed with the statement } \\
(\%)\end{array}$} & \multicolumn{2}{|c|}{$\begin{array}{c}\text { Share of respondents that } \\
\text { neither agreed nor disagreed } \\
\text { with the statement or could } \\
\text { not say their opinion }(\%)\end{array}$} \\
\hline & $\begin{array}{l}\text { HTA Core } \\
\text { Model for } \\
\text { medical and } \\
\text { surgical } \\
\text { interventions } \\
\quad(n=24)\end{array}$ & $\begin{array}{l}\text { HTA Core } \\
\text { Model for } \\
\text { diagnostic } \\
\text { technologies } \\
\quad(n=15)\end{array}$ & $\begin{array}{l}\text { HTA Core } \\
\text { Model for } \\
\text { medical and } \\
\text { surgical } \\
\text { interventions } \\
\quad(n=24)\end{array}$ & $\begin{array}{l}\text { HTA Core } \\
\text { Model for } \\
\text { diagnostic } \\
\text { technologies } \\
\quad(n=15)\end{array}$ & $\begin{array}{l}\text { HTA Core } \\
\text { Model for } \\
\text { medical and } \\
\text { surgical } \\
\text { interventions } \\
\quad(n=24)\end{array}$ & $\begin{array}{l}\text { HTA Core } \\
\text { Model for } \\
\text { diagnostic } \\
\text { technologies } \\
\quad(n=15)\end{array}$ \\
\hline Feasibility of the general concept & 83 & 93 & 13 & 7 & 4 & 0 \\
\hline $\begin{array}{l}\text { Ability of the domains to represent } \\
\text { the main aspects of HTA }\end{array}$ & 92 & 93 & 0 & 0 & 8 & 7 \\
\hline $\begin{array}{l}\text { Ability of the assessment elements } \\
\text { within various domains to cover } \\
\text { the domains adequately }\end{array}$ & 88 & 93 & 4 & 0 & 8 & 7 \\
\hline $\begin{array}{l}\text { Adequate description of the } \\
\text { assessment elements in the } \\
\text { element cards }\end{array}$ & 92 & 80 & 4 & 13 & 4 & 7 \\
\hline $\begin{array}{l}\text { Adequacy of the definition of the } \\
\text { Core through the importance and } \\
\text { transferability of assessment } \\
\text { elements (the Core Matrix) }\end{array}$ & 83 & 80 & 4 & 0 & 13 & 20 \\
\hline $\begin{array}{l}\text { Lack of major conceptual conflicts } \\
\text { or inconsistencies in the Model }\end{array}$ & 88 & 80 & 4 & 0 & 8 & 20 \\
\hline $\begin{array}{l}\text { Adequate description of terms in } \\
\text { the Model }\end{array}$ & 88 & 87 & 4 & 0 & 8 & 13 \\
\hline $\begin{array}{l}\text { Feasibility of the suggested process } \\
\text { through which the Model } \\
\text { translates into practical research }\end{array}$ & 58 & 67 & 17 & 0 & 25 & 33 \\
\hline
\end{tabular}

Other uses for the HTA Core Model were presented during the EUnetHTA Project, that is, using the Model for extracting data from existing HTA reports and for educational purposes. These applications are worth considering in the future.

\section{Applying the Model: The Core HTAs}

Two assessments were conducted using the HTA Core Model, one on drug-eluting stents and another for multislice computed tomographic angiography. These aimed at testing the model and providing feedback for model development. Hence, they are not intended for actual decision making. Due to the relatively long production process, the up-todateness of their content at the time of publishing could not be guaranteed. Details on the Core HTAs and their production process are available elsewhere in this journal and in respective documents $(8 ; 9 ; 23)$.

\section{Validation}

Eight general questions were used during validation to gauge the overall feasibility of the HTA Core Model. Most respondents ( $\geq 80$ percent) agreed or strongly agreed with seven of these, supportive of the current Model. Agreement was less strong concerning the process for conducting Core
HTAs. Even here, most respondents still supported the design. Strong disagreement was recorded for only three questions regarding the intervention model, representing only 4 percent of responses to those questions (Table 3).

Validation of the two models contained also more detailed questions regarding each domain and the assessment elements. Two to nine persons provided feedback on each domain. They were rather satisfied with the domains, with most criticism in the domains of ethical analysis, social aspects, and safety. More practicality was called for in domain descriptions and more detail on methodology. The overlap of issues and variety in the detail of definitions raised concern. Eleven respondents used an ongoing or recently published HTA project to test the individual assessment elements of the first draft of the intervention model. In these projects, 58 percent of the suggested assessment elements were discussed, with wide variation across domains. The domains for ethical analysis, as well as social and legal aspects were seldom included in actual HTAs. The feedback on the intervention model induced substantial changes in three domains (safety, social, and organizational). The second validation round (on the diagnostic model) brought positive feedback from nearly all respondents, and led to the removal of some overlapping issues. 


\section{Handbook}

The Handbook (19) is in an online format containing three sections. The introduction presents the basic principles of the HTA Core Model. The second section provides practical guidance on using the Model to produce a Core HTA, written primarily for users of the online HTA Core Model-an electronic tool that is under construction. The third section contains methodological guidance for finding answers to research questions of the Core HTA.

The relatively brief Handbook connects with more extensive materials that are part of the HTA Core Model. For instance, the Handbook gives an overview of domain descriptions, but users can easily access the more extensive domain descriptions in the Model.

\section{DISCUSSION}

The HTA Core Model is a new tool to foster a collaborative way of assessing health technologies, aiming at promoting international use of HTA results and avoiding duplicate work. It is still in a paper format, but an online system that provides users with an easy-to-use interface to the Model and its applications is being built. An electronic version can also be used for educational purposes.

The HTA Core Model employs a broad and comprehensive perception of HTA. A clear advantage is the inclusion, definition, and framing of often forgotten areas: ethical, social, organizational, and legal aspects. Development and use of the HTA Core Model may allow these research perspectives to become more commonplace in HTA-bringing HTA back to its roots in 1970s and closer to its definition $(2 ; 3 ; 17)$.

Globalization of healthcare interventions challenges HTA institutions to develop methods to share their assessment work and results. Future HTAs based on the HTA Core Model can probably be more easily utilized in another region or country. This was a key goal of the EUnetHTA Project: to increase opportunities for sharing information through clear, structured Core HTAs. A description of the content of Core HTAs will enhance the use of available HTA pieces—be they completely new HTAs with prospectively produced content or existing HTAs from other settings.

Domains of HTA. The domains apply several research methods, mostly utilizing standard evidence-based approaches. The systematic literature review remains the main methodology for most domains. When reliable randomized clinical trial data are missing, other types of study designs should be considered, for example, register studies and surveys. The preferred or most suitable methodologies vary widely between the assessment elements. In general, the HTA Core Model respects state-of-the-art research methods within any of the domains.
Use of the HTA Core Model requires a basic understanding of various research paradigms. The traditional diffusion model of the positivist research paradigm applies in defining and answering questions on clinical effectiveness, safety, accuracy, and cost-effectiveness. In contrast, the translational model of the interpretative research paradigm is more useful in mapping contextual factors, describing stakeholder experiences of ethical, organizational, and patient issues, and understanding barriers and facilitators of implementing technologies (14). Although transferability is a key characteristic of core information as defined by the HTA Core Model, implementation of any technology may require further translational data on environments where the technology will be used and on the people using it.

Due to overlap between domains, cooperation between domains will be needed when conducting HTAs, particularly if people working on the domains are not the same. Domain analyses seem to benefit from being done in a certain order. This was not obvious at the outset, complicating the Core HTA process in this project. For example, economic modeling requires information on the effectiveness, use, and safety of the technology. Ethical analysis utilizes perspectives from other domains in analyzing ethical implications and perspectives. Furthermore, ethical analysis should be tightly integrated into other domains already when framing the research questions (24).

The need for a separate domain for accuracy of diagnostic tests was subject to intensive discussion. Issues considered within accuracy are closely related both to description and technical characteristics of technology and clinical effectiveness. Because accuracy has its own particular properties, we started with allocating a separate domain for it. As a result of many conceptual discussions and practical feedback, we decided to include it as a topic within the clinical effectiveness domain. This choice was not straightforward in conceptual terms, but allows a more contained basic structure of the Model.

Role of Core HTAs. Core HTAs collect and analyze the information on technologies from several angles, providing a foundation for local considerations and informed decisions. Core HTAs are not meant to replace national HTAs, which cater better to local circumstances and needs. Neither is the intention to supersede national or local decision making through supranational recommendations on technologies. This is why Core HTAs do not contain policy recommendations.

Standardization. We have explicitly avoided focusing too much on research methodologies; there is no need to rewrite the guidance available in textbooks and methodology guides. Instead, we aimed at writing overviews of methodological guidance to assist practical HTA work, referring to existing sources. The HTA Core Model has an element of standardization as regards the information structure of an 
assessment; even this may raise some opposition, but we believe its benefits far outweigh its restrictions.

Element cards enable the use of standards in performing HTAs. It is possible, for instance, to define that the records of the European Medicines Agency (EMEA) and the U.S. Food and Drug Administration (FDA) should be searched regarding the approval status of a given technology. In the current versions of the models, such guidance takes the form of recommendations or suggestions. Stricter standards require policy discussions within the future Collaboration.

We did not want to interfere with local HTA processes. The only process guidance can be found in the introduction of the model and addresses the ethics of HTA (10;11). That guidance in our view is not standardization, but a guideline for ethical conduct while doing HTA.

Generic Flexibility. The extent and level of detail in an HTA depend on the technology being assessed. These are considered when applying the HTA Core Model to a single HTA. The process of considering the relevance of each assessment element and translating the relevant issues into practical research questions is meant to ensure that the model adapts to various situations without losing its generic nature. Reasons for excluding elements from an analysis should be recorded in the report as they may provide useful information for report users.

Reporting. The HTA Core Model provides assessments with a common structure for presenting the findings. Various domains, topics, and issues can be used as headlines in a traditional report. The structure also enables storage of the assessment in electronic databases and supports applications for combining and analyzing HTA results. A pilot system is under construction.

Informatics. Recent developments in informatics, particularly the Semantic Web and structuring information have been considered when building the Model (4). In our era of information overload, it is essential to assign meanings to produced information for easier retrieval with high sensitivity and specificity. This aspect of the Model enables future development in HTA implementation, for example, in the context of decision-support systems and clinical practice guidelines.

Core or Not-Core? Including assessment elements in, or excluding them from, the core is driven by usability of the information across national borders or other contexts. An element outside the core can be important and worth considering in an HTA. Again, important but nontransferable assessment elements are excluded from the core, but such elements may provide useful or even critical information. To guide decision making, they need to be addressed locally by individual HTA agencies.

Several domains contain important issues of limited transferability. The domain teams were concerned about the possible exclusion of these issues from the Model. During the project, however, a borderline category was created for issues that were important, but only partially transferable. The intention here was to define the role of these elements at the end of the project, when the number of each importancetransferability combination would be known. The current final version of the Model excludes only few combinations of importance and transferability (Table 2). Further piloting of the Model will further clarify the core status of elements.

Judging transferability and importance by group consensus was not straightforward. However, the exercise helped identify further discussion topics. The current judgments of importance and transferability represent an "educated guess" to be revised when experience with Core HTAs is gained.

True Collaboration in Challenging Circumstances. Development of the HTA Core Model was a difficult and time-consuming process. Opportunities for face-toface meetings during the methodological work were limited. Teams in many domains were active and mutually supportive, making the development process a real European cooperation. Some Domain teams had difficulties engaging people to comment or contribute, leaving the primary investigators to carry much of the workload. Many investigators carried on from the first to the second Model, creating continuity.

The assessment element approach required a true cultural change from the traditional HTA report to a set of assessment elements in the HTA Core Model. All Domain teams first struggled with the concept of small, independent pieces of information in a database. During the process, teams agreed that the information structure could be useful and relevant for the assessment process, even if some issues had never been reported in their traditional HTA reports. Using the traditional structure would have risked missing these issues. Defining assessment elements became easier as the teams became more familiar with the approach and accepted the concept of the new Model.

Language barriers were detected among those who were not native speakers of English language. Although it was agreed that many languages could not be used concurrently while performing an assessment, the Core HTAs as end products could be translated into different languages.

Face-to-face meetings were important when designing the model and conducting Core HTAs. Future European collaboration should encourage cooperation to facilitate progress.

Validity and Future Development. The products probably require further refinement, as many new concepts and methods have been introduced. The formal validation process and public feedback provided valuable comments and identified development needs. Most feedback was positive and supportive of the model, affirming the face validity of the approach. Further piloting of Core HTAs, free from the pressure of developing a novel model, will reveal the true value of the system. The availability of an online version will enable changes that increase user-friendliness and 
usability. Much work remains to be done by future EUnetHTA Collaboration.

The current HTA Core Model needs further development to ensure optimal usefulness. The level of detail and scope of the assessment elements, and consequently the granularity of the Model across domains varies. Terminology and definitions require further harmonization and standardization, and a sustainable solution is needed on issues that overlap different domains.

The categories of assessment elements (core/not-core) originate from consensus processes in domain teams. Importance and transferability were reconsidered during validation. Further testing may necessitate changes in the categories, so the role of the elements may still change. We intend to follow a robust development policy in future EUnetHTA Collaboration, managing versions of the HTA Core Model properly. Readers of Core HTAs should be able to check which version of the model was used for assessment.

It was not a surprise for us that the domains for ethical analysis and social aspects were not agreed on as often as other domains. Within these domains, research methodology in the healthcare context is not yet well established and, hence, differences of opinion are more likely to exist. These domains are subject to more cultural and social differences than the more prevalent domains.

The current applications for medical and surgical interventions and diagnostics do not cover all technologies. Other applications will surely be needed, for instance, for screening technologies or administrative support systems. Our experience in developing two applications suggests that they largely overlap. Hence, new applications can build on earlier work.

A Community Trademark has been applied for to protect the HTA Core Model. Terms of use have been published by the EUnetHTA Collaboration.

\section{CONCLUSIONS AND RECOMMENDATIONS}

The HTA Core Model is a tool to support European collaboration in producing and sharing HTAs. The domain structure is based on earlier work, but the detailed formulation of assessment elements is novel. Within the tight schedule it was possible to produce two pilot Core HTAs. The multinational teams representing a variety of disciplines agreed on the results. Wide agreement on the principles applied was a key to success. The current Model can be expected to cover essential features of HTA.

The Model can also be used in education and training, since it makes the definition of HTA tangible.

In piloting the Model, several new challenges were identified. The Core HTAs are consequently not optimal, but rather should be viewed as a first test of the Model. For full use, an online version of the Model needs to be implemented. In addition, overlaps and timing of work within various domains require further attention. The Model must be tested for many technologies, and HTA organizations around the world are encouraged to test and apply the Model in their work and to provide feedback to EUnetHTA on their experiences.

Developing further applications of the Model, for example, screening and other population-level interventions, or various systems that support care, would be a valuable step forward.

\section{SUPPLEMENTARY MATERIALS}

Supplementary Figure 1

Supplementary Table 1

Supplementary Table 2

Supplementary Table 3

www.journals.cambridge.org/thc2009001

\section{CONTACT INFORMATION}

Kristian Lampe, MD, (kristian.lampe@thl.fi), Senior Medical Officer, Finnish Office for Health Technology Assessment, National Institute for Health and Welfare, P.O. Box 30, 00271 Helsinki, Finland

Marjukka Mäkelä, MD, PhD, MSc (marjukka.makela@ thl.fi), Director, Finnish Office for Health Technology Assessment, National Institute for Health and Welfare, P.O. Box 30, 00271 Helsinki, Finland; Professor, Department of General Practice, University of Copenhagen, P.O. Box 2099, 1014 Copenhagen K, Denmark

Marcial Velasco Garrido, MD, MPH (marcial.velasco@ tu-berlin.de), Research Assistant, Health Care Management, Technische Universität Berlin, Straße des 17. Juni 135, Secr. H80, Berlin 10623, Germany

Heidi Anttila, PT, PhD (heidi.anttila@thl.fi), Special Researcher, Finnish Office for Health Technology Assessment, National Institute for Health and Welfare, P.O. Box 30, 00271 Helsinki, Finland

Ilona Autti-Rämö, MD, PhD (ilona.autti-ramo@kela.fi), Expert Consultant, Finnish Office for Health Technology Assessment, National Institute for Health and Welfare, P.O. Box 30, 00271 Helsinki, Finland; Head of Health Research, Research Department, The Social Insurance Institution, Nordenskiöldinkatu 12, 00250 Helsinki, Finland; Adjunct Professor, Department of Pediatric Neurology, Hospital for Children and Adolescents, University of Helsinki, Lastenlinnantie 2, 00250 Helsinki, Finland

Nicholas J. Hicks, MBBS, BA (Hons), FFPH (hicks@ soton.ac.uk), Consultant in Public Health Medicine, National Coordinating Centre for Health Technology Assessment, University of Southampton, Alpha House, University of Southampton Science Park, Southampton SO16 7NS, UK

Bjørn Hoffman, PhD (b.m.hofmann@medisin.uio.no), Researcher, Norwegian Knowledge Center for the Health Services, P.O. Box 7004, St. Olavs plass, N-0130 Oslo, Norway; Professor, Institute for Health, Care and Nursing, 
University College of Gjøvik, P.O. Box 1, N-2802 Gjøvik, Norway

Juha Koivisto, PhD (juha.koivisto@thl.fi), Senior Researcher, Unit for Innovations and Good Practices, National Institute for Health and Welfare, Lintulahdenkuja 4, 00530 Helsinki, Finland

Regina Kunz, MD, MSc (Epi) (rkunz@uhbs.ch), Professor in Clinical Epidemiology, Institute for Clinical Epidemiology and Biostatistics, University Hospital Basel, Hebelstrasse 10, 4031 Basel, Switzerland

Pia Kärki (pia.karki@thl.fi), Secretary, Finnish Office for Health Technology Assessment, National Institute for Health and Welfare, P.O. Box 30, 00271 Helsinki, Finland

Antti Malmivaara, MD, PhD (antti.malmivaara@thl.fi), Senior Medical Officer, Finnish Office for Health Technology Assessment, National Institute for Health and Welfare, Lintulahdenkuja 4, 00530 Helsinki, Finland

Kersti Meiesaar, PhD (kersti.meiesaar@ut.ee), Associate Professor, Department of Public Health, University of Tartu, 19 Ravila Street, Tartu, Estonia 50411

Päivi Reiman-Möttönen, PHN, MSocSc (paivi.reimanmottonen@thl.fi), Planning Officer, Finnish Office for Health Technology Assessment, National Institute for Health and Welfare, P.O. Box 30, 00271 Helsinki, Finland

Inger Norderhaug, PhD (inn@nokc.no), Research Director, Evidence Based Practice, Norwegian Knowledge Center for the Health Services, P.O. Box 7004, St. Olavs Plass, N0130 Oslo, Norway; Associate Professor, Institute for Public Health, University of Troms $\varnothing, 9037$ Troms $\varnothing$, Norway

Iris Pasternack, MD (iris.pasternack@thl.fi), Research Officer, Finnish Office for Health Technology Assessment, National Institute for Health and Welfare, P.O. Box 30, 00271 Helsinki, Finland

Alberto Ruano-Ravina, MSc, PhD (alberto.ruano. ravina@sergas.es), Senior Technician, Galician Agency for Health Technology Assessment, Galician Department of Health, Edif Admtvo San Lázaro s/n, Santiago Compostela, 15781, Spain; Associate Professor, Preventive Medicine \& Public Health, University of Santiago de Compostela, San Francisco s/n, Santiago de Compostela, La Coruña, Spain

Pirjo Räsänen, PhD (pirjo.rasanen@thl.fi), Senior Researcher, Finnish Office for Health Technology Assessment, National Institute for Health and Welfare, P.O. Box 30, 00271 Helsinki, Finland

Ulla Saalasti-Koskinen, MSc (ulla.saalasti-koskinen@ thl.fi), Research Officer, Finnish Office for Health Technology Assessment, National Institute for Health and Welfare, Lintulahdenkuja 4, 00530 Helsinki, Finland

Samuli I. Saarni, MD, PhD, MSocSc (samuli.saarni@ helsinki.fi), Senior Researcher, Finnish Office for Health Technology Assessment, National Institute for Health and Welfare, P.O. Box 30, 00271 Helsinki, Finland; Adjunct Professor, Department of Psychiatry, Helsinki University and Helsinki University Hospital, Välskärinkatu 12, 00250 Helsinki, Finland
Laura Walin, PhD, LLM (laura.walin@helsinki.fi), Researcher, Criminal and Procedural Law, University of Helsinki, P.O. Box 4, 00014 Helsinki, Finland

Finn Børlum Kristensen, MD, PhD (fbk@sst.dk), Director, Danish Centre for Health Technology Assessment, National Board of Health, Islands Brygge 67, DK2300 Copenhagen S, Denmark; Adjunct Professor, Faculty of Health Sciences, University of Southern Denmark, Winsløwparken 19, 3, Odense C, DK 5000, Denmark

\section{REFERENCES}

1. Banta D, Oortwijn W. Health technology assessment and health care in the European Union. Int J Techol Assess Health Care. 2000;16:626-635.

2. Banta HD, Luce BR. Health care technology and its assessment. An international perspective. Oxford: Oxford University Press; 1993.

3. Banta D. What is technology assessment? Int J Technol Assess Health Care. 2009;25(Suppl 1):7-9.

4. Berners-Lee T, Hendler J, Lassila O. The semantic web. A new form of web content that is meaningful to computers will unleash a revolution of new possibilities. 2001, [updated May 2001]. Available at: http://www.sciam.com/article. cfm?id=the-semantic-web (accessed December 18, 2008).

5. Busse R, Orvain J, Velasco M, et al. Best practice in undertaking and reporting health technology assessments. Working group 4 report. Int J Technol Assess Health Care. 2002;18:361422.

6. Draborg E, Gyrd-Hansen D, Poulsen PB, Horder M. International comparison of the definition and the practical application of health technology assessment. Int J Technol Assess Health Care. 2005;21:89-95.

7. EUnetHTA. 2008 Work Package 4. Technical report. Available at: http://ec.europa.eu/health/ph_systems/docs/eunethta_report _en.pdf.

8. EUnetHTA. 2008. Work Package 4. Core HTA on drug eluting stents (DES), [updated December 31, 2008]. http://www. eunethta.net/Public/EUnetHTA_Deliverables_project_20062008/.

9. EUnetHTA. 2008. Work Package 4. Core HTA on multislice computed tomography (MSCT) coronary angiography, [updated December 31, 2008]. Available at: http://www. eunethta.net/Public/EUnetHTA_Deliverables_project_20062008/.

10. EUnetHTA. 2008. Work Package 4. HTA Core Model for diagnostic technologies $v$ 1.Or. Available at: http://www.eunethta. net/Public/EUnetHTA_Deliverables_project_2006-2008/.

11. EUnetHTA. 2008. Work Package 4. HTA Core Model for medical and surgical interventions v 1.Or. Available at: http:// www.eunethta.net/Public/EUnetHTA_Deliverables_project_ 2006-2008/.

12. International Network of Agencies for Health Technology Assessment. 2001. A checklist for health technology assessment reports. Stockholm: [updated December 18, 2008]. Available at: http://www.inahta.org/HTA/Checklist/ (accessed December $18,2008)$. 
13. Jonsson E, Banta HD, Henshall C, Sampietro-Colom L. Summary report of the ECHTA/ECAHI project. Int J Technol Assess Health Care. 2002;18:218-237.

14. Koivisto J, Anttila H, Ikonen T, Reiman-Möttönen P. Relational evaluation of the patient aspects of health technology. 2008 Annual EASST Meeting, August 20-23, Rotterdam, The Netherlands.

15. Kristensen FB, Lampe K, Chase DL, et al. Practical tools and methods for health technology assessment in Europe: Structures, methodologies, and tools developed by the European network for Health Technology Assessment, EUnetHTA. Int J Technol Assess Health Care. 2009;25(Suppl 2): 1-8.

16. Kristensen FB, Horder M, Poulsen PB, eds. Health technology assessment handbook. 1st ed. Copenhagen: Danish Centre for Evaluation and Health Technology Assessment; 2001.

17. Kristensen FB, Mäkelä M, Allgurin Neikter S, et al. European network for Health Technology Assessment, EUnetHTA: Planning, development, and implementation of a sustainable European network for Health Technology Assessment. Int J Technol Assess Health Care. 2009;25(Suppl 2):107-116.

18. Kristensen FB, Sigmund H, eds. Health technology assessment handbook. 2nd ed. Copenhagen: Danish Centre for Evaluation and Health Technology Assessment, National Board of Health,
2007. Available at: http://www.sst.dk/Udgivelser/2008/Health \%20Technology\%20Assessment\%20Handbook.aspx (accessed December 15, 2008).

19. Lampe K, Pasternack I, eds. 2008. HTA core model handbook. Available at: http://www.eunethta.net/Public/EUnetHTA_ Deliverables_project_2006-2008/.

20. Latour B. Science in action: How to follow scientists and engineers through society. Cambridge MA: Harvard University Press; 1987:132-144.

21. Liberati A, Sheldon TA, Banta HD. EUR-ASSESS Project Subgroup report on Methodology. Methodological guidance for the conduct of health technology assessment. Int J Techol Assess Health Care. 1997;13:186-219.

22. National Information Center on Health Services Research and Health Care Technology (NICHSR), 2004. HTA 101 Fundamental concepts, [updated March 4, 2008]. Available at: http://www.nlm.nih.gov/nichsr/hta101/ta10104.html\#Heading 10 (accessed December 18, 2008).

23. Pasternack I, Anttila H, Mäkelä M, et al. Testing the HTA Core Model: Experiences from two pilot projects. Int J Technol Assess Health Care. 2009;25(Suppl 2):21-27.

24. Saarni S, Hofmann B, Lampe K, et al. Ethical analysis to improve decision-making on health technologies. Bull World Health Organ. 2008;86:617-623. 